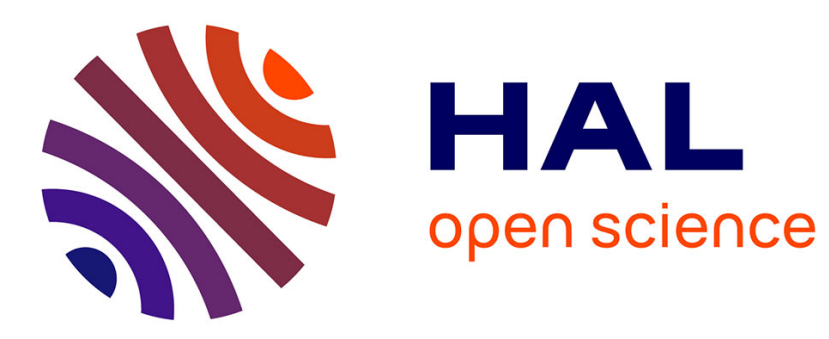

\title{
Assessing students wellbeing in a spatial dimension
}

Sebastien Fleuret, Jérôme Prugneau

\section{To cite this version:}

Sebastien Fleuret, Jérôme Prugneau. Assessing students wellbeing in a spatial dimension. The Geographical Journal, 2014, 181 (2), pp.110-120. 10.1111/geoj.12098 . hal-03337707

\section{HAL Id: hal-03337707 \\ https://univ-angers.hal.science/hal-03337707}

Submitted on 8 Sep 2021

HAL is a multi-disciplinary open access archive for the deposit and dissemination of scientific research documents, whether they are published or not. The documents may come from teaching and research institutions in France or abroad, or from public or private research centers.
L'archive ouverte pluridisciplinaire HAL, est destinée au dépôt et à la diffusion de documents scientifiques de niveau recherche, publiés ou non, émanant des établissements d'enseignement et de recherche français ou étrangers, des laboratoires publics ou privés. 


\title{
Assessing students' wellbeing in a spatial dimension
}

\author{
SÉBASTIEN FLEURET* AND JÉRÔME PRUGNEAU† \\ *MSH, Université d'Angers, 5 bis Boulevard Lavoisier, 49045 Angers Cedex 01, France \\ E-mail: sebastien.fleuret@univ-angers.fr \\ +UFR Lettres, Langues et Sciences Humaines, Université d'Angers, 11 Boulevard Lavoisier, 49045 \\ Angers Cedex 01, France \\ E-mail: jerome.prugneau@univ-angers.fr \\ This paper was accepted for publication in May 2014
}

\begin{abstract}
This paper examines the issues related to the double-sided dimension of wellbeing: subjective and objective. In the theoretical framework developed by Fleuret and Atkinson (2007, The New Zealand Geographer 63 106-29), spaces of wellbeing are shaped by four dimensions (spaces of security, spaces of capability, therapeutic spaces and integrative spaces). In the case of the student population in Angers, we observe a major imbalance: the component that really stands out is capability, which is quite logical because students are a population in a transition between youth and adulthood. The results reveal that the student population has a specific relation to space due to a transitory presence in the university town, with, as a consequence, a simultaneous embedding in different places. This could explain why the students do not perceive the characteristics of place to be a major influence on their wellbeing; instead it is the perception they have of their wellbeing that influences their perception of place.
\end{abstract}

KEY WORDS: wellbeing, spaces of wellbeing, Student transition, university town, France, health geography

\begin{abstract}
The geography of wellbeing focuses on all the connections that men create between themselves and their territory in order to understand the satisfaction they find in these links as well as the inequalities the latter cause.
\end{abstract}

Bailly (1981)

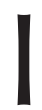
$\mathrm{n}$ the 1970s a large number of studies attempted to come up with indicators for wellbeing, quality of life and life satisfaction from the point of view of social and territorial development. This work tried to provide objective ways of quantitatively measuring wellbeing (Perret 2002). Over the past few years there has been a growth of interest within geography in subjective assessments of wellbeing, including an increased use of qualitative research (Conradson 2012). This attention to subjective wellbeing is based on a collection of case studies which constitute a body of knowledge which determines the boundaries of a geography of wellbeing. This paper examines the specific case of the wellbeing of students situated in a mid-sized town in France. Beyond the case study itself, the aim is to integrate the empirical results into a wider conceptual frame using the theoretical framework developed by Fleuret and Atkinson (2007).
The first section of this paper sets the context of the study, the second describes the material and methods used, and the third presents the results of a survey carried out on 1178 students. These results are then discussed in the final part which emphasises the importance of linking the spatial dimension of wellbeing to both a social and temporal categorisation of the population groups under study.

\section{Context}

Wellbeing is now of major interest across many different academic disciplines. So geography of wellbeing is a growing field of research. The development of this branch of geography is linked to the development of a critical geography engaged with theory (Litva and Eyles 1995). Atkinson et al. (2012) also link the geography of wellbeing to the use of wellbeing as a governing policy concept. These developments have put the question of wellbeing on the agenda for geographers who have been examining the various aspects of this concept. Indeed this question of wellbeing is found in some sub-disciplines of geography. In health geography, the WHO definition of health as a state of complete wellbeing 
rather than the absence of illness, as well as the epistemological debate at the end of the 1990s about the cultural turn, resulted in a new trend for the discipline (Kearns and Moon 2002). In the field of environmental studies, the quality of life, often merged with wellbeing, was used to characterise the impact of environmental changes on the life of populations with the development of the notion of an environmentally friendly way of living (Rogerson 1995; Pacione 2003). In social geography, wellbeing is perceived as a material constraint of daily life (Bailly 1981) and as a pivotal issue for the articulation of spatialised social policies (Atkinson et al. 2012) and individual and collective interactions (Fleuret 2007). The concept of wellbeing demands an interdisciplinary approach, drawing on the economic sciences through to the social and cognitive sciences, and reflecting the complexity of wellbeing which makes it so difficult to grasp. To paraphrase Kearns and Gesler (1998, 6), the evolution of the 'young' geography of wellbeing can be characterised as a double transformation: from space as a container to space as an active agent in the shaping of wellbeing, and from place as a location to place as, simultaneously, landscape, centre of societal activities and nexus of shared and personal meaning. It is in this context that the framework of the spaces of wellbeing (Fleuret and Atkinson 2007) was developed; it frames the study presented here.

The spaces of wellbeing framework associates different approaches from several disciplines in the field of social sciences. First, drawing on Maslow (1954), it is possible to seek to assess the satisfaction of everyone's needs according to the hierarchy of these needs, that is, to distinguish primary or basic needs at the basis of the pyramid and personal fulfilment at the apex. Second, inspired by the theory of relative standards (Schyns 1998), wellbeing must be understood within any given setting, or in other words, wellbeing is contingent. It means, for example, that different perceptions of wellbeing can result from equivalent material living conditions, depending on the perception that each individual has of their relative position in society (Staudinger et al. 1999). Even when living in fairly good material conditions, if people perceive themselves as of lower standing than their neighbours, their perception of their own wellbeing will be negatively affected. The engagement with the relativity of standards presents a challenge to the measurement of wellbeing. What is captured by these measures corresponds more often to perception of quality of life (in terms of individual feeling of comfort or happiness) than to a global assessment of an entire population's wellbeing. A third way to assess wellbeing is to consider the capacity of individuals to choose and realise their ambitions. This is related to the theory of capability (Sen 1992) in which both the freedom to choose and the conditions to realise such choices are highly situation dependent.
Fleuret and Atkinson state that these three theories confront two conflicting dimensions: objective, referring to living conditions and both individual and collective resources; and subjective, expressed in terms of goals, perceptions and both individual and cultural values.

Clearly, wellbeing is a complex and ambiguous notion. As pointed out by Bailly $(1981,11)$, wellbeing '... results from the relationship between an individual and/or a group and a state or a thing; [wellbeing] is an interpretation'. Defining wellbeing as a research object is then difficult, as wellbeing is a complicated synthesis between objective and subjective, material and immaterial, individual and collective. Thus the ongoing challenge for geographers is to rethink the issue of wellbeing by contextualizing it into both personal and populationbased experiences of place' (Kearns and Collins 2010, 27)

To deal with this complexity, we chose to build our methodology upon a pre-existing theoretical framework. A distinctive feature of the framework of Fleuret and Atkinson (2007) is that it does not originate from an evaluation on an individual scale but from an assessment of space's potentialities. To be considered a space of wellbeing, a space needs four properties: it has to be capacitating, integrative, secure and therapeutic. The potential for a place to contribute to wellbeing can be assessed by studying these four properties. As stated before, what constitutes wellbeing expresses huge variability, from one individual, group or geographical context to another. Thus, identifying universal indicators is fraught with difficulties, particularly for subjective wellbeing, and attempts towards this are still unfinished (Perret 2002) ${ }^{1}$. The framework of Fleuret and Atkinson can be used to understand the contextual dimensions of individuals that influence their wellbeing. Some recent studies (Hall 2010; Nordbakke and Schwanen 2014) have applied the framework in this way. Indeed it does not set any types of indicator or any determined scales of analysis. In accordance with the relativity of standards, it aims to elaborate a tool for observation which is to be adapted to each context for each property. This approach makes it possible to capture what Atkinson et al. (2012) refer to as contextualised influences on individualised wellbeing. It should be highlighted that even though wellbeing can be understood and conceptualised in many different ways, individualistic understandings - wellbeing as a property of individuals or a state in which they reside - has become especially popular with the rise of neoliberalism across the global North (Binkley 2011). Geographers have criticised these individual perspectives, arguing that wellbeing also includes collective dimensions and can be shaped by spatial contexts in which people live and spend time (Atkinson 2013). From this angle, wellbeing cannot be understood if the constant, complex, recursive interplay between individuals and their spatial 
contexts is ignored. The framework developed by Fleuret and Atkinson offers a tool to understand the ways in which spatial contexts mediate and shape individuals' wellbeing because space is studied for its virtues which are conducive or unconducive to wellbeing.

On this basis, this paper presents the case of Angers, a mid-sized town (ca. 150000 inhabitants, Census 2010) in western France. To study the spatial dimension of students' wellbeing, we consider two contextual elements relative to this population.

First, the status of student is related to age and can be characterised as a transitional phase. Going to university and becoming a student manifest various aspects of transition: an academic transition from high school to the higher education system, in which the cultural capital has a massive influence (Beaud 2002; Bourdieu and Passeron 1964), and an individual transition from youth to adulthood and particularly from dependence to independence (Hopkins 2006; Christie 2009; Holdsworth 2009).

Second, this transition is also spatial. A majority of French students leave their parents' home to go to university. This means living in a larger town, and/or in new urban spaces such as a town centre or a campus outside the town. The university town becomes a transitional place since most of the students maintain or develop connections with other places and build only a temporary and partial embeddedness in the university town, sharing their spatial embeddedness between several places (Prugneau 2012). Other data from our survey, as well as a set of interviews conducted with 215 students between 2010 and 2013, show that they rely on different places in this transition. The university town often appears less important than their former living places - where they grew up - when it comes to feeling at home, social relationships, leisure and sports activities, mobilising resources during or after studies or planning their future. They use some of its resources, they select the amenities they need but are not really involved in everyday life in the city, having a limited knowledge of the town. Even if they feel well there, many students tend to leave as soon as possible during and after their studies ${ }^{1}$.

Consequently, the temporality and the spatial embeddedness specific to students are two contextual elements that are fundamental when studying their wellbeing. From this population and within the above-mentioned theoretical frame, the aim of our paper is to study the interactions between perception of wellbeing and perception of space for students, a social group which is still under-researched in geographical studies of wellbeing.

\section{Data and methodology}

In order to examine those interactions, a survey, developed by a multidisciplinary research team comprising geographers, sociologists, psychologists and economists, was conducted in 2009 with 1178 students of the university. The aim was to assess the living conditions of the 20000 students of the university. It focused particularly on issues such as poverty, precariousness and vulnerability, health, and access to and use of different services in the university and in the town (Université d'Angers 2011, 2014).

The questionnaire was divided into different sections (identification, budget, health, wellbeing, studies, dwelling, transport). This paper is mainly based on the results from the wellbeing section, which are compared with data from the other sections. The questions in the wellbeing section were specifically designed with the Fleuret and Atkinson framework in mind.

The sample of students represents $20 \%$ of the first- and third-year population and is statistically representative of the following criteria: year of study, receivers of a means-tested grant or not, gender and faculty. Students were directly questioned in their place of study, in groups of 30-50 individuals, over a period of three weeks at the end of the first semester. Each group was invited to sit in a classroom for a $2 \mathrm{~h}$ session during which some geography students specially trained for the purpose were present to help them in case of any difficulties encountered. The survey was long (325 questions) but not all the students had to answer every question. According to their profile, the students were able to skip certain sets of questions (for instance, 40 questions on sports could be skipped by those not interested in sport). On average, students took $50 \mathrm{~min}$ to complete the questionnaire. Tests have been conducted to evaluate fatigue effects due to the questionnaire's length. These have shown that the rate of non-response does not increase across the survey and that the quality of the answers at the beginning and at the end of the questionnaire is comparable.

The questionnaire was designed through collaboration among different actors of the university and based on a review of French and international articles about students' living conditions (Gruel et al. 2009), youth transitions (Van de Velde 2008; Holdsworth 2009) and university towns and campuses (Gumprecht 2003; Munro and Livingston 2012). The items were also chosen to be comparable to national data produced by the French Students' Life Observatory (OVE) and to other surveys launched by French universities.

In relation to these surveys, the main contribution of the Angers study lies in the fundamental place given to the spatial dimension. The student's answers are always linked to their place of residence, to their place of origin and to the place where their parents live. This approach is in line with the idea that considering the spatial dimension is essential in order to understand the transition that occurs during student life. Student transition is one of the modalities of youth transition, a phase in the building of the 


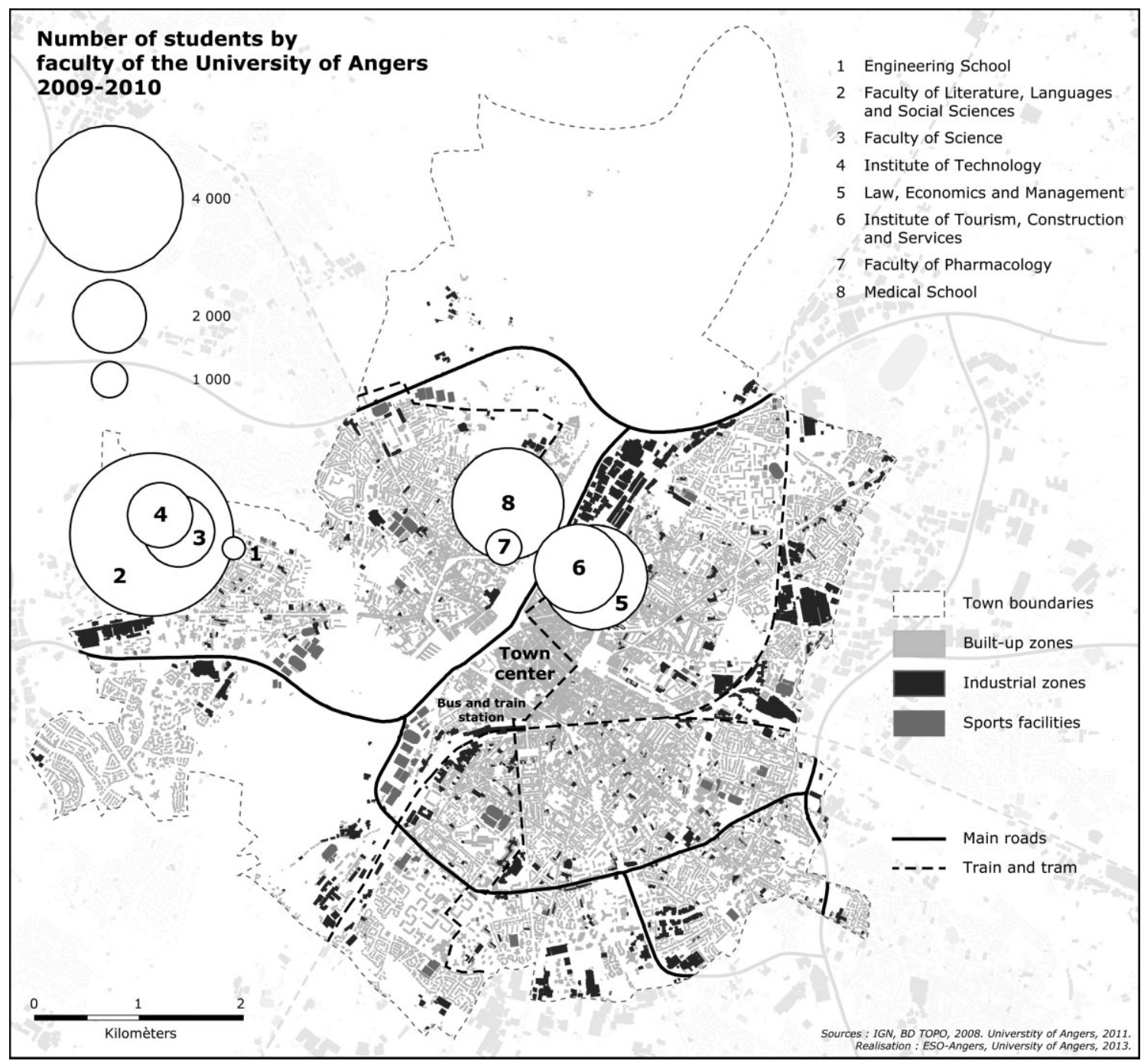

Figure 1 The University of Angers, its eight faculties and their numbers of students (2009-2010)

independence of young people. It associates an activity (college studies), an age of life (between youth and adulthood), a multispatial embedding (in the university town or the campus and in the parents' hometown), a housing change (moving to an individual residence) and a progressive control of a personal budget.

Compared with studies from other countries, a second original aspect arises from some specificities of the French universities in the international landscape of higher education. First, French universities are less selective socially than in many countries because of lower fees and because the French exam at the end of secondary studies gives access to any kind of university studies, without any point system ${ }^{2}$. Second, French campuses appear more as places of study than as places of life with the vast majority of students living in the town and in the area around, not directly on the campus. A third distinctive feature is that whereas many international surveys focus on one aspect of student life or one particular group, the Angers study aims for an overall perspective. In many universities the campuses are either a real town within the town or based outside of the town. In the case of Angers, three campuses are spread out across the town (see Figure 1): one in the centre, one on the other side of the river and one in a peripheral location. These campuses do not function independently and the services or the jobs available on the sites are limited. This means that the students 
Table 1 Eight questions used to assess wellbeing

On a scale from 1 to 10 , how would you rate your wellbeing?

What would you need to improve this score?

During the last 4 weeks, did you feel?

satisfied with your life, optimistic about the future, proud of your studies, in good physical form, in good psychological form, none of these

Compared to your fellow students, would you say that you have life which is:

better, worse, the same, I don't know

Evaluate the quality of your dwelling:

very good, good, correct, so-so, bad, substandard and unsafe

Do you think your dwelling is adapted to your student work?

absolutely, relatively, relatively not, not at all

Characterise your neighbourhood:

wealthy, average, disadvantaged, I don't know

Characterise your living environment:

very good, good, correct, so-so, bad, very bad

have to make use of the amenities of their neighbourhoods and the town centre, in which $40 \%$ of students reside. The survey sample is distributed in the same way over the three sites as the student population at large.

A series of eight questions (Table 1) were about wellbeing. They focused on the satisfaction of needs, perception of relative standards, current and future capability, objective and subjective perceptions of wellbeing, and the quality of spaces (dwelling and personal environment).

Two complementary questions at the end of the questionnaire asked for a self-assessment ('good', 'bad' or 'no answer') of student life quality and happiness. The results from the survey inform us about the students' wellbeing from their own perspective. They are cross compared with objective indicators from other sections of the survey. These indicators can be grouped into categories (housing, access to services, transport, social life, life project, financial resources, use and perception of the university and of the town). The detail of the questions used in the paper will be given case-by-case in the results section.

\section{Results}

The survey enables an examination of the links between place and wellbeing in the light of the perception the students have of their wellbeing and their place of living. These perceptions are both objective and subjective. They bring qualitative
Table 2 How would you rate your wellbeing on a scale of 1 (low) to 10 (high)?

\begin{tabular}{lrrr}
\hline Wellbeing & \multicolumn{1}{c}{ N } & & \\
\hline Less than 3 & 22 & $1.9 \%$ & $12.8 \%$ \\
From 3 to 5 & 126 & $10.9 \%$ & \\
From 6 to 8 & 841 & $72.4 \%$ & $87.2 \%$ \\
More than 8 & 172 & $14.8 \%$ & $100 \%$ \\
Total & 1161 & $100 \%$ & \\
\hline
\end{tabular}

elements about the university town, which is considered here as a potential space of wellbeing.

\section{Perceptions of wellbeing}

The students were asked to evaluate their level of wellbeing on a scale from 1 (lowest) to 10 (highest). Another question was about their satisfaction with life, inspired by Diener and Lucas Satisfaction with Life Scale (1999), but phrased differently ${ }^{3}$. We did not aggregate this question's results into an overall score but analysed each item individually. Even though the participating students declare a high level of wellbeing (average 7.13), there are still nearly 13\% who have a negative (5 and less) perception of their wellbeing (Table 2). This subjective self-evaluation is probably a mix of affective components (positive and negative feelings) and cognitive components (assessment of life satisfaction and domain satisfaction), as suggested by Diener et al. (1999 2009). The aim of this question was precisely to mix these two types of components.

When asked to compare their life with the life of their fellow students, the students' global perception ranges from neutral to positive. Concerning the relative standards, the results show that many students feel average and representative of quite a homogeneous group $(59.2 \%$ estimate that their life is as good as or better than others students' life). The fact that in France going to university is a relatively ${ }^{4}$ collective experience can explain this neutral/positive perception. In addition to the survey, we carried out 215 qualitative in-depth interviews which reveal, on this particular point, that university students do not see themselves as an elite youth, but they know that some more disadvantaged young people do not have the opportunity to go to university. One thing is constant in the survey: very few people describe themselves as deprived, excluded or different (5.3\%).

Although the student population appears to be relatively homogeneous when assessing their level of subjective and relative wellbeing, slight differences emerge upon examining their expectations. The students were asked about what they would need in order to improve their level of wellbeing. Their answers to this open-ended question were recorded and nine categories appeared: material conditions, 
Table 3 What would need to be improved to increase your wellbeing?

\begin{tabular}{lrr}
\hline Improvements & $N$ & $\%$ \\
\hline Capacity to build plans for the future & 228 & $21.2 \%$ \\
Material conditions & 220 & $20.4 \%$ \\
Psychological wellbeing & 198 & $18.4 \%$ \\
Romantic relationship & 141 & $13.1 \%$ \\
Physiological wellbeing & 133 & $12.3 \%$ \\
Other relationships & 102 & $9.5 \%$ \\
Desire for new horizons & 23 & $2.1 \%$ \\
Nothing & 17 & $1.6 \%$ \\
Universal aspirations & 15 & $1.4 \%$ \\
Total & 1077 & $100 \%$ \\
\hline
\end{tabular}

capacity to plan for the future, romantic relationship, physiological wellbeing, psychological wellbeing, other relationships, desire for new horizons, universal aspirations, nothing. Only a few respondents referred to two categories. Thus only the first category quoted was kept in the results (Table 3). These answers can be linked to several of the four spaces of wellbeing as figured in the Fleuret and Atkinson framework (see right column, Table 3 ). Within our sample, $21.2 \%$ declare that they need to build plans for the future in order to increase their wellbeing, which connects to the space of capability. A total of $20.4 \%$ declare that they need to improve and to secure their material living conditions ${ }^{5}$; this relates to the need for spaces of security. In both cases, what they would need is the removal of some uncertainties: material, professional, psychological, romantic or those about studies. This introduces a temporal dimension: would these uncertainties be short or long term? When would the student be rid of them? We will return to these temporal questions in our conclusion.

Unsurprisingly, we observe a difference between the self-rated wellbeing of those desiring improvement and the rest of the sample except for physiological issues. But this difference varies according to the category of improvement desired and is more important for psychological issues (related to health in the framework) than for the categories related to capability.

The students of the University of Angers claim to have quite a high level of wellbeing and only very rarely perceive themselves as different to the group to which they belong. This reveals the existence of a sort of a collective image of student wellbeing, based on a normative evaluation which mixes objective criteria (quality of life) and subjective criteria (happiness). Even though $86 \%$ declare a very positive level of wellbeing with only $5.3 \%$ stating that their life is not as good as that of their peers, a majority indicate room for the improvement of their wellbeing. This is mostly described in terms of an increase in their ability to do certain things (have a clear vision of their future, study in good conditions, feel better psychologically or physically, live a romantic relationship). In this context, one can wonder if and how the spatial dimension of the student experience impacts the students' wellbeing and if their level of wellbeing modifies their perception of the university town.

\section{Students' wellbeing, reading through the framework}

To integrate the issue of place into the questions on the students' wellbeing, we decided to call upon the spaces of wellbeing as defined by Fleuret and Atkinson. An initial question had been designed to find out about the four virtues (capacitating, integrative, therapeutic, secure) highlighted in the framework of the spaces of wellbeing: 'Do you have any concerns at the moment?' (Table 4).

Four items were proposed, each one corresponding to one of the framework's dimensions. It was completed by a set of questions in order to evaluate wellbeing: one about the self-assessment of wellbeing, one open question about the best conditions to improve wellbeing. Another question examined the level of personal satisfaction of life and another one was based on the relative standards (Staudinger et al. 1999).

In the health section of the questionnaire, several questions aimed at assessing wellbeing, for instance by seeking to know if students' living conditions had any influence on their health or if some situations (stress due to studies, multiple job-holding, housing problems) could have symptomatic effects.

To study the geographical dimension of student wellbeing the answers to all these questions have been cross compared with other data from the survey revealing spatial variables: students' living environment (housing, neighbourhood), their social networks and their possible scattering, their mobilities, their use of space and their spatial embeddedness. Six students out of ten declared no concerns; so we focused on the others, studying concern after concern (they were allowed to declare several concerns at the same time), property of space after property of space.

The students declaring capability concerns also declare a below average level of wellbeing (6.34/7.13). About their environment (housing or neighbourhood $\left.{ }^{6}\right)$, a difference appears between the appreciation based on objective or subjective criteria. Regarding the objective criteria (for example the comfort of housing), the group declaring capability concerns (among whom 76.8\% evaluate the level of comfort as high or very high) does not really differ from the group without any capability concerns $(78.6 \%)$. When it comes to subjective criteria, for example, when asked 'Do you consider that your dwelling gives you good conditions in which to study?', the students with capability concerns have a more negative perception $(30.6 \%$ consider their dwelling as 'totally adapted' compared with $45.6 \%$ of 
Table 4 Do you have any concerns at the moment?

\begin{tabular}{|c|c|c|c|c|c|c|c|c|}
\hline Wellbeing concerns & $\begin{array}{c}\text { Number of } \\
\text { students }\end{array}$ & $\begin{array}{c}\text { Number of } \\
\text { quotes } \\
(N=507)\end{array}$ & $\begin{array}{c}\% \text { of } \\
\text { quotes }\end{array}$ & $\begin{array}{l}\text { Wellbeing of } \\
\text { those who } \\
\text { express this } \\
\text { concern } \\
(\max =10)\end{array}$ & $\begin{array}{c}\text { Wellbeing } \\
\text { if no other } \\
\text { concern }\end{array}$ & $\begin{array}{l}\text { Wellbeing of } \\
\text { those who do } \\
\text { not express the } \\
\text { concern }\end{array}$ & $\begin{array}{l}\text { Wellbeing of } \\
\text { those who } \\
\text { express two } \\
\text { concerns } \\
(N=61)\end{array}$ & $\begin{array}{l}\text { Wellbeing of } \\
\text { those who } \\
\text { express three } \\
\text { concerns } \\
(N=6)\end{array}$ \\
\hline $\begin{array}{l}\text { Capability to fulfil } \\
\text { your desires }\end{array}$ & & 318 & $25.5 \%$ & 6.34 & 6.53 & 7.42 & & \\
\hline Health & & 108 & $8.7 \%$ & 6.48 & 6.92 & 7.20 & & \\
\hline Integration & 440 & 48 & $3.9 \%$ & 5.36 & 5.69 & 7.20 & 5.30 & 4.33 \\
\hline Security/precariousness & & 33 & $2.6 \%$ & 6.27 & 7 & 7.15 & & \\
\hline None & 738 & 738 & $59.3 \%$ & 7.56 & & 6.42 & & \\
\hline
\end{tabular}

those without capability concerns). The same observation can be made for the self-evaluation of the quality of student life, judged as good or very good by only $49.4 \%$ of the students with capability concerns, as opposed to $73.5 \%$ of the others.

With wellbeing dropping to 5.6 (average $=7.13$ ), the lack of integration impacts all the measurable factors. It results in feelings of isolation $(33 \%$ compared with 7\%), but at the same time these students appear very dependent on family support. This is a form of spatial isolation: there is still a connection with the family but there is a real geographical distance. This can be linked to the financial question as students' resources generally have three possible origins: money transfers from their family, state help, or work. The students with integration concerns are more often in an unbalanced situation, with only one source of financial support which is the family. The foreign students are overrepresented in that subgroup, in which students are deeply embedded in two different places (place of origin and place of study). This complicates the assessment of the spatial dimension of their wellbeing. The lack of integration weighs on the relative standards $(29.2 \%$ say their life is not as good as their peers' vs only $5.3 \%$ in the whole panel or $8.2 \%$ for the ones with capability problems). Cross tabulation with a range of general questions of the survey reveals a high level of difficulty for the students declaring concerns of wellbeing connected with integration; e.g. $43.8 \%$ do not balance their budget (vs $30.9 \%$ ).

For the people declaring wellbeing concerns connected to health, angst (wellbeing: 6.48/7.13) appears to be related to chronic illnesses (57.4\% have a chronic illness or are often ill, compared with 10.6\% for the others). They are less likely to receive financial help from their family. So they are more often forced to work during the university year $(29.7 \%$ compared with $18.6 \%$ for the others) and their earnings are more often used to cover basic needs and university expenses. Despite their salaries, more of them have difficulties balancing their budget (40.7\% vs 29.9\%).
This weaker family support can also be observed through their answers to the question 'Who do you go to for health information?': the doctor is more often mentioned and the parents less often, which differentiates them from the other groups. There are more cases of conflict with the parents $(20.4 \%$ vs $10.2 \%$ ) for the students declaring wellbeing concerns connected to health. This accumulation of difficulties can explain poorer appreciations on their space and quality of life: their level of wellbeing seems to impact their perception of space. Again, as with the integration factor, the foreign students are overrepresented in this subgroup.

The group concerned with concerns of wellbeing connected to security and precariousness is the smallest, with only 33 people (wellbeing: 6.27/7.13). Their difficulties are twofold: they suffer from material precariousness $(87.9 \%$ declare problems when it comes to balancing their budget compared with $29.3 \%$ for the others) and they are pessimistic about their future $(54.5 \%$ think their professional project has only an average or weak chance of happening compared with $41.5 \%$ for the others). They are the only subgroup in which the socio-professional category of parents plays a role, with an overrepresentation of working class households $(63.7 \%$ compared with $32.3 \%$ for the rest of the panel), and the only subgroup living entirely inside the town while wanting to move. Security and precariousness problems are probably worse since the methodology based on presence in the university excluded those who rarely, if ever, attend. Finally, the students declare very few security and precariousness problems, but those issues appear more clearly in the answers to the general questions about situation, needs and expectations.

\section{Discussion/conclusion}

On the basis of the Angers case, it appears that the level of wellbeing impacts in a different way the perception of the quality of space. Nearly all the students with a wellbeing level of 9 or 10 perceive 
Table 5 How would you characterise your living environment?

\begin{tabular}{lcc}
\hline & $\begin{array}{c}\% \text { for pop } \\
\text { with wellbeing }\end{array}$ & $\begin{array}{c}\% \text { for pop } \\
\text { with wellbeing } \\
\text { Perception of their } \\
\text { living environment }\end{array}$ \\
\hline Excellent & 8 & $<5$ \\
Good & $43.4 \%$ & $11.5 \%$ \\
Average & $53.3 \%$ & $44.3 \%$ \\
Adequate & $3.3 \%$ & $26.2 \%$ \\
Bad & $0 \%$ & $13.1 \%$ \\
No answer & $0 \%$ & $1.6 \%$ \\
Total & $0 \%$ & $3.3 \%$ \\
\hline
\end{tabular}

their living environment as good or excellent, whereas the students with a wellbeing level under 5 are more negative about their living environment, without actually characterising it as bad (Table 5). For us, this means that the perceived level of wellbeing and the perception of one's living environment influence each other.

When the students are asked not to express their perception of their environment but to assess their social environment with items such as 'wealthy', 'average' or 'disadvantaged', there is no difference between those with a high level of wellbeing and those with a low level. Apparently, there are two manners to characterise space: one influenced by perceived wellbeing and the other not. In the first case, the evaluation of the environment seems to be affective 'It's MY living environment' whereas in the second case, more distance is taken with the use of objectified categories. This suggests a real difference between the appreciation of the material conditions and the subjective perception of wellbeing (the students with a low level of wellbeing are more likely to say: 'my neighborhood is OK but I'm not satisfied with my living environment'). This finding is reinforced by the results in Table 6 .

We observed that the characterisation of dwelling and neighbourhood was influenced by the presence (or absence) of wellbeing issues. For example, capability concerns do not significantly impact the appreciation of housing when it is based on objective criteria (i.e. comfort) but they lead to a more negative perception when the evaluation criteria are subjective (i.e. 'the quality of my housing impacts my studying conditions').

Based on our empirical study, we can conclude that the Fleuret and Atkinson framework provides a useful and effective tool to formulate the questions and analyse the answers. Each characteristic of places promoting wellbeing can be linked with, simultaneously, individual characteristics and sociospatial trends (Figure 2). At this point it seems interesting to discuss our use of the theoretical
Table 6 Wellbeing concerns and evaluation of neighbourhood and dwelling

\begin{tabular}{lcc}
\hline & $\begin{array}{c}\text { Students } \\
\text { declaring at least } \\
\text { one concern }\end{array}$ & $\begin{array}{c}\text { Students not } \\
\text { declaring any } \\
\text { concern }\end{array}$ \\
\hline $\begin{array}{l}\text { Comfort of dwelling } \\
\text { Good and very good }\end{array}$ & 74.8 & 79.7 \\
Bad and very bad & 2 & 1.5 \\
Correct and so-so & 20.7 & 15.4 \\
$\begin{array}{l}\text { Dwelling adapted to studies } \\
\text { Absolutely }\end{array}$ & 33.9 & \\
Relatively & 49.1 & 46.2 \\
Relatively not & 12.5 & 43.5 \\
Absolutely not & 2.5 & 5.8 \\
Characterisation of the neighbourhood & 1.6 \\
Wealthy & 30 & 28.3 \\
Average & 63.8 & 64 \\
Disadvantaged & 6.1 & 5 \\
Characterisation of the living environment & \\
Good and very good & 78.2 & 90.2 \\
Bad and very bad & 3.2 & 1 \\
Average and so-so & 19.8 & 7.7 \\
\hline
\end{tabular}

framework. While it is based on an assessment of the potentialities of spaces, our results come from data collected at an individual scale. This does not mean that we moved away from the framework. Quite the contrary we systematically tried to understand in which way the individual answers had a spatial meaning. This is what we call the socio-spatial trends in Figure 2. If we look at the classification of the problems when related to spaces of capability, spaces of integration, spaces of security and therapeutic spaces (Table 3), we do not suggest that place is the primary or even a main significant cause of the problem (other factors can have an influence) but we observe a relationship between the way students characterise space and the way they characterise their wellbeing. The inclusion of a control group (by conducting the study in two different university cities) would have made it easier to identify the contribution of place to students' wellbeing. But this internal survey of the University of Angers was not solely dedicated to our research purposes.

The use of this framework is a means to inform public policies about the issues that need to be addressed with respect to the spatial dimensions of wellbeing. One of the results of the present case study lies in a major imbalance in the distribution of the answers between the four categories of spaces of wellbeing. Here, students' wellbeing is clearly linked to the issue of capability to fulfil their desires. Health also emerges as important, although it is less frequently mentioned. The number of students pointing out issues of integration or security/ 


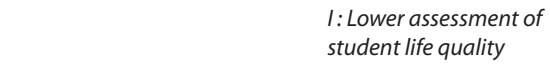

I: Material precariousness difficulties planning the future

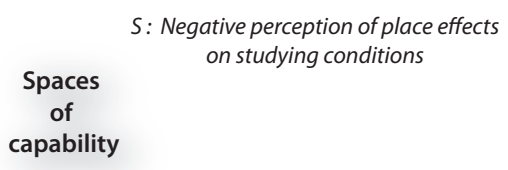

I: Feeling of being less supported and unstable financial situation

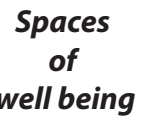

S: Over representation of working class origins, Located within the university town but desire to move out

$\begin{array}{cc}\begin{array}{c}\text { Spaces } \\ \text { of } \\ \text { security }\end{array} & \begin{array}{c}\text { Spaces } \\ \text { of } \\ \end{array} \\ \text { well being }\end{array}$

I: Individual characteristics

$\mathrm{S}$ : Socio-Spatial trends
Weaker family support and less likely to have recourse to family or relatives for health issues

\section{Therapeutic \\ spaces}

S: Accumulation of socio-economic difficulties, poorer appreciation of place and quality of life. Over-representation of foreigners
S: Form of spatial isolation, simultaneous link to two places (place of origin, place of study). Over-representation of foreigners

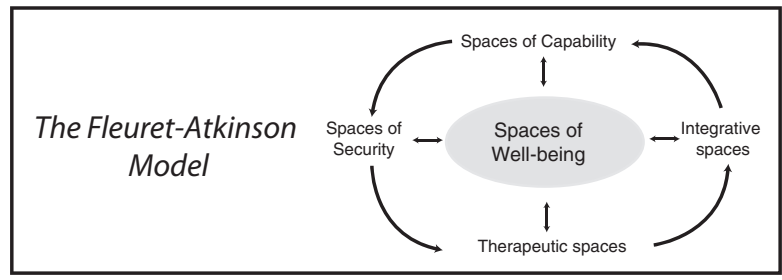

Figure 2 Students' wellbeing read through the conceptual framework

precariousness is too low to be really significant; these aspects would need further investigation. To go back to Table 3, we can connect the ways students think they can improve their wellbeing to the four dimensions of the theoretical framework. We had eight categories that we interpreted as linked to the four dimensions of the framework.

To conclude, we formulate the hypothesis that the students have a specific relation to space and time. Their presence in the university town is a moment of transition between youth and adulthood, dependence and autonomy, a limited period of time during their studies. The consequence is a lack of territorial embeddedness, which could explain why there are few indications of the characteristics of place influencing their wellbeing. What is important here is the transitional status of students in the town, the reason why students envisage their wellbeing in other spaces: where they come from and continue at least partially to live (at their parents') and where they will build their family and working life (often not yet determined). For example, $37 \%$ of the students who live on their own in the university town say that they 'feel home' at their parents' rather than at their student residence. These students spend an average of five nights a month at their parents' and half of them purchase cultural or sports activities in their hometown. So if we want to understand the wellbeing of students, a life course approach that positions their current stage in life and residential situation in a wider trajectory or path must be adopted. Recent special issues of Area (2011, volume 43, issue 4) and Environment \& Planning A (2011, volume 43, issue 3) point out this renewed interest in life course analysis in geography.

Therefore, it seems that the original 'spaces of wellbeing' perspective by Fleuret and Atkinson needs to be expanded into a 'space-times of wellbeing' framework. Indeed a space can be a space of wellbeing just for a given lapse of time and in the case of a spatial practice determined by factors such as age or a daily activity (studies, work...). This indication leads to another question. Students' spaces of wellbeing are not exclusively devoted to the students and the university studies, since students live and study within the urban space where other people live too, as shown by research work on studentification (Hubbard et al. 2012). How is this urban space shared and regulated, knowing that spaces of wellbeing for some are not necessarily spaces of wellbeing for others? Thus, future research is needed on other categories of population, on other ages of life (young households, retired people) to see whether and how the spatial dimensions may impact their wellbeing or 
if, like the students, their level of wellbeing influences their perception of space. It could reveal whether spaces of wellbeing are the same or different across socio-demographic groups. This work has been engaged in other spatial contexts for the persons with disabilities (Hall 2010) or the older people (Nordbakke and Schwanen 2014).

Another particularity of the student population gives food for thought. Some go back and forth between a flat in the university town and their parents' home which is sometimes far away (or other places such as the home of their partner, family, partner's family or friends). As a result, to characterise their wellbeing does not mean studying a clearly defined, located and limited space but rather several interrelated and discontinuous spaces and discontinuous social networks. Again, some expansions are indicated to the original framework to allow for the relations between different and sometimes discontinuous spaces of daily life.

In the end, this study of university students' wellbeing shows the importance of a spatialised conceptual framework and invites us to multiply the number of case studies so as to refine this framework.

\section{Acknowledgements}

The authors would like to acknowledge the contribution made by the referees of this paper.

\section{Notes}

1 Only a few students start their professional career in Angers, probably due to the size of the town and to its rank into the French urban hierarchy.

2 In the French system, selective curriculums exist but are not integrated into the university (the so-called 'grandes écoles' and their preparatory courses, for example).

3 'During the last 4 weeks, did you feel? satisfied with your life, optimistic about the future, proud of your studies, in good physical form, in good psychological form, none of these'.

4 Considering that two-thirds of a generation are qualified to go to the university and that lots of the future elite go to other structures in the higher education system (cf note 2).

5 The material living conditions are not only an issue of comfort. They are more about the lack of precariousness, thus a material, financial and social wellness, as well as the lack of certainty regarding the capacity to maintain this situation or to improve it (it is important to keep in mind that in France, where the access to university is not expensive, many students live in precarious situations).

6 Both where evaluated on a scale (from 1 to 10) based on the comfort of the housing and on the perception of the neighbourhood as more or less agreeable.

\section{References}

Atkinson S 2013 Beyond components of wellbeing: the effects of relational and situated assemblage Topoi 32 137-44
Atkinson S, Fuller S and Painter J 2012 Wellbeing and place Ashgate, Farnham

Bailly A 1981 Géographie du bien-être PUF, Paris

Beaud S 2002 80\% au bac et après? Les enfants de la démocratisation scolaire La Découverte, Paris

Binkley S 2011 Happiness, positive psychology and the program of neoliberal governmentality Subjectivity 4 371-94

Bourdieu P and Passeron J-C 1964 Les héritiers Minuit, Paris

Christie H 2009 Emotional journeys: young people and transitions to university British Journal of Sociology of Education 30 123-36

Conradson D 2012 Wellbeing: reflexions on geographical engagements in Atkinson S, Fuller S and Painter J Wellbeing and place Ashgate, Farnham 15-34

Diener E and Lucas R E 1999 Explaining differences in societal levels of happiness: relative standards, need fulfillment, culture, and evaluation theory Journal of Happiness Studies 1 41-78

Diener E, Lucas R E, Schimmack U and Helliwell J 2009 Well-being for public policy Oxford University Press, New York

Diener E, Suh E M, Lucas R E and Smith H E 1999 Subjective well-being: three decades of progress Psychological Bulletin 125 276-302

Fleuret S 2007 Bien-être, santé et géographie in Fleuret $\mathbf{S}$ and Thouez J-P, Géographie de la santé, un panorama Editions Economica-Anthropos 72-87

Fleuret S and Atkinson S 2007 Wellbeing, health and geography: a critical review and research agenda The New Zealand Geographer 63 106-29

Gruel L, Galland O and Houzel G eds 2009 Les étudiants en France. Histoire et sociologie d'une nouvelle jeunesse PU Rennes

Gumprecht B 2003 The American college town Geographical Review 93 51-80

Hall E 2010 Spaces of wellbeing for people with learning disabilities Scottish Geographical Journal 275-84

Holdsworth C 2009 Going away to uni: mobility, modernity and independence of English higher education students Environment and Planning A 41 1849-64

Hopkins P E 2006 Youth transitions and going to university: the perceptions of students attending a geography summer school access programme Area 38 240-7

Hubbard P, Sage J and Smith D 2012 The rapidity of studentification and population change: there goes the (student)hood Population, Space and Place 18 597-613

Kearns R and Collins D 2010 Health geography in Brown T, McLafferty S and Moon G eds Companion to Health and Medical Geography Wiley-Blackwell, Oxford 15-32

Kearns R and Gesler W 1998 Putting health into place. Landscape, identity \& wellbeing Syracuse University Press, Syracuse, NY

Kearns R and Moon G 2002 From medical to health geography: novelty, place and theory after a decade of change Progress in Human Geography 26 605-25

Litva A and Eyles J 1995 Coming out: exposing social theory in medical geography Health and Place 1 5-14

Maslow A 1954 Motivation and personality Harper and Row, New York 
Munro M and Livingston M 2012 Student impacts on urban neighbourhoods: policy approaches, discourses and dilemmas Urban Studies 49 1679-94

Nordbakke S and Schwanen T 2014 Well-being and mobility: a theoretical framework and literature review focusing on older people Mobilities 9 104-29

Pacione M 2003 Urban environmental quality and human wellbeing - a social geographical perspective Urban Environmental Quality and Human Wellbeing 65 19-30

Perret B 2002 Indicateurs sociaux, état des lieux et perspectives Rapport au Conseil de l'Emploi, des Revenus et de la Cohésion Sociale (CERC), Paris

Prugneau J 2012 From hometown to university town: a transitional phase in a transitional place, communication 2nd International Conference on Geographies of Education, University of Loughborough

Rogerson R J 1995 Environmental and health-related quality of life: conceptual and methodological similarities Social Science \& Medicine 41 1373-82
Schyns P 1998 Crossnational differences in happiness: economic and cultural factors explored? Social Indicators Research 43 $3-26$

Sen A 1992 Capability and well-being in Sen A and Nussbaum M eds The quality of life Clarendon Press, Oxford 30-53

Staudinger U M, Fleeson W and Baltes P B 1999 Predictors of subjective physical health and global well-being: similarities and differences between the United States and Germany Journal of Personality and Social Psychology 76 305-19

Université d'Angers 2011 Rapport d'enquête sur les conditions de vie étudiante (enquête 2009) Angers

Université d'Angers 2014 d'enquête sur les conditions de vie étudiante (enquête 2011) Angers

Van de Velde C 2008 Devenir Adulte. Sociologie comparée de la jeunesse en Europe PUF, Paris 